03,13

\title{
Исследование этапов превращения кремния в карбид кремния в процессе атомного замещения методами полного внешнего отражения рентгеновских лучей и рентгеновской дифрактомерии
}

\author{
(C) С.А. Кукушкин ${ }^{1}$, А.В. Осипов ${ }^{1}$, Е.В. Осипова ${ }^{1}$, В.М. Стожаров ${ }^{2}$ \\ ${ }^{1}$ Институт проблем машиноведения РАН, \\ Санкт-Петербург, Россия \\ ${ }^{2}$ Научно-технический центр „Новые технологии“, \\ Санкт-Петербург, Россия \\ E-mail: sergey.a.kukushkin@gmail.com
}

Поступила в Редакцию 3 ноября 2021 г.

В окончательной редакции 3 ноября 2021 г.

Принята к публикации 4 ноября 2021 г.

Методами рентгеновской дифракции и полного внешнего отражения рентгеновских лучей (рефлектометрии) исследованы последовательные стадии синтеза эпитаксиальных пленок $\mathrm{SiC}$ на поверхностях $\mathrm{Si}(100)$, (110) и (111) методом замещения атомов. Изучены данные об эволюции превращения поверхностей (100), (110) и (111) $\mathrm{Si}$, в поверхности $\mathrm{SiC}$. Выполнен сравнительный анализ ренгеноструктурного качества слоев $\mathrm{SiC}$, выращенных на $\mathrm{Si}$ методом замещения атомов, с качеством слоев $\mathrm{SiC}$, выращенных фирмой Advanced Epi стандартным CVD-методом. Описывается модифицированная методика метода полного внешнего отражения рентгеновских лучей, основанная на измерениях интенсивности отраженных рентгеновских лучей при помощи специального параболического зеркала. Показано, что метод полного внешнего отражения позволяет получить важную информацию о степени шероховатости поверхности слоев $\mathrm{SiC}$, эволюции их кристаллической структуры и энергии плазмонов в процессе превращения $\mathrm{Si}$ в $\mathrm{SiC}$.

Ключевые слова: полное внешнее отражение, рентгеновская рефлектометрия, карбид кремния, плазмоны.

DOI: 10.21883/FTT.2022.03.52093.232

\section{1. Введение}

Явление полного внешнего отражения рентгеновских лучей (ПВО), при котором рентгеновское излучение не заходит во вторую среду и практически полностью отражается на границе раздела сред с различными показателями преломления [1-5], наблюдается при углах скольжения, меньших некоторого критического $\alpha_{c}$. Если рентгеновский луч падает на границу раздела сред и угол его падения меньше $\alpha_{c}$, то рентгеновские лучи зеркально отражаются, проникая при этом на 1-2 nm вглубь вещества. Критический угол $\alpha_{c}$ чрезвычайно мал и зависит от электронной плотности материала. Чем выше угол падающего рентгеновского пучка по отношению к критическому углу, тем на большую глубину рентгеновские лучи проникают в материал. Для материалов, поверхность которых можно считать идеально плоской, отражательная способность резко уменьшается при углах, больших критического. Возрастание шероховатости поверхности материала приводит к резкому снижению отражательной способности этой поверхности. Если материал, имеющий плоскую поверхность, используется в качестве подложки и равномерно покрыт слоем другого материала, электронная плотность которого отличается от электронной плотности исходной поверхности, то при отражении от поверхности тонкой пленки и от границы раздела между подложкой и пленкой рентгеновские лучи будут интерферировать друг с другом, образуя осцил- ляционный рисунок. В первом приближении, интенсивность рассеянных образцом лучей, пропорциональна квадрату модуля от Фурье преобразования электронной плотности [1-5]. Таким образом, профиль плотности электронов можно рассчитать из измеренной интенсивности рентгеновских лучей, а затем можно определить толщины слоев, их шероховатость и ряд других свойств. В частности, толщина пленки может быть определена из анализа периодичности колебаний (по аналогии с эллипсометрией), а информация о поверхности и межфазных границах пленок может быть найдена из угловой зависимости амплитуды колебаний. На этих измерениях и основан метод рефлектометрии [1-5]. В последнее время метод рентгеновской рефлектометрии начал широко использоваться для определения толщины, плотности и шероховатости как однослойных, так и многослойных пленочных структур [2]. Достоинства рентгеновской рефлектометрии заключаются в том, что она позволяет определять: шероховатость поверхностей и границ раздела сред (типичный размер неоднородностей - менее $5 \mathrm{~nm}$ ), толщину слоя материала (обычно для слоев тоныше $200 \mathrm{~nm}$ ), распределение плотности электронов и внутреннее строение сложных структур [2].

Согласно классической теории рентгеновской дифракции $[6,7]$, показатель преломления $n$ рентгеновских лучей в любом твердом теле меньше единицы. Причем в рентгеновской области спектра электромагнитного излучения, показатель преломления связан с декремен- 
том показателя преломления $\delta=1-n$, который прямо пропорционален объемной плотности атомов $N_{a V}[6,7]$ :

$$
\delta=\frac{\lambda^{2} e^{2}}{2 \pi m c^{2}} N_{a V} f(0),
$$

где $\lambda=1.5406 \AA$ - длина волны рентгеновского излучения $\mathrm{Cu}_{\mathrm{K} \alpha 1} ; e-$ заряд электрона; $m$ - масса электрона; $c$ - скорость света; $f(0)$ - атомный фактор рассеяния в направлении падающего рентгеновского излучения (для одноатомного вещества атомный фактор равен порядковому номеру элемента $Z$ ). Отметим, что данное определение показателя преломления не совсем корректно [8]. Строго говоря, это определение основано на предположении, что длина электромагнитной волны $\lambda \gg a$, где $a$ - межатомное расстояние. Формула (1) получена из условия связи вектора электрической индукции с вектором напряженности электрического поля при помощи диэлектрической проницаемости. Согласно [8], использовать выражение (1) можно лишь в случае, если частота рентгеновского излучения $\omega$ много больше частоты вращения электронов в атоме $\omega_{0}$, т. е. $\omega \gg \omega_{0}$. Это условие, как правило, выполняется для внешних электронных оболочек в атомах, но оно может не выполняться для внутренних электронных оболочек тяжелых атомов. Если это так, то следует принять во внимание тот факт, что обычное определение диэлектрической проницаемости, как коэффициента, связывающего электрическую индукцию с напряженностью электрического поля, не является полным. Вклад в обычный коэффициент диэлектрической проницаемости вносят лишь внешние электроны. Вклад внутренних электронов вычисляется путем усреднения по всему объему электронных оболочек, а диэлектрическая проницаемость и, соответственно, показатель преломления становятся зависящими от пространственных координат $\mathbf{r}[2,8]$. При малых значениях разности между волновыми вектором падающего и рассеянного излучения, плотность электронов $n_{e}(\mathbf{r})$ сводится к усредненной электронной плотности $\bar{n}_{e}[2,8]$. В этом случае при прохождении рентгеновских лучей через кристалл происходит их преломление, в полном соответствии с законами геометрической оптики. Следует, однако, помнить, что шероховатость будет приводить к дифракции рентгеновских лучей в тонких поверхностных слоях. Очевидно, что излучение, исходящее в результате дифракции, и излучение, образующееся в результате отражения, могут наложиться друг на друга.

Положение максимума на кривых отражения при малых (близких к нулю) углах скольжения $\alpha$ однозначно определяет показатель преломления рентгеновских лучей и, как показано в [2,9], связано с ним простым соотношением

$$
n=\cos \alpha \text {. }
$$

Если поверхность образца шероховатая, то часть излучения не отражается в зеркальном направлении, а рассеивается по другим углам. Образуется так называемое диффузное отражение. При этом интенсивность зеркального отражения уменьшается. Степень уменьшения зеркального отражения определяется особенностями рельефа поверхности. В работах [1-5] это явление было подробно исследовано.

Измеряя декремент показателя преломления $\delta$, по формуле (1) можно определить плотность электронов в единице объема $n_{e}=N_{a V} f(0)$. Поскольку плотность атомов $N_{a V}=N_{A} \rho / \mu$, где $N_{A}$ - число Авогадро, $\rho-$ плотность вещества, $\mu$ - молекулярный вес, то по значению $\delta$ можно определить массовую плотность $\rho$ исследуемого вещества. Наличие некоторого переходного слоя переменного состава определяется по характеру спада кривой рассеяния. Однако для этого требуется использования специальных математических моделей и специализированных компьютерных программ [2,7]. Метод рентгеновской рефлектометрии может быть реализован на рентгеновском дифрактометре, позволяющем проводить измерения в области малых углов падения рентгеновского пучка на образец. Метод ПВО в настоящее время интенсивно развивается. Этот метод широко используется при исследования тонких пленок различных веществ, пленок Ленгмюра-Блоджетта, разнообразных адсорбированных слоев. Все возможности анализа структуры вещества этим методом до конца еще не выяснены [2]. Ясно одно - метод ПВО весьма перспективен, как метод анализа тонкой структуры поверхностных слоев кристаллов различной природы. В частности, оказалось, что если на кристалл падает плоская рентгеновская волна с волновым вектором $\mathbf{k}_{0}$ и для некоторого вектора обратной решетки кристалла $\mathbf{h}$ выполняется условие Вульфа-Брэгга $\left(\mathbf{k}_{0}+\mathbf{h}\right)^{2}=k_{0}^{2}$, то амплитуда рассеянной рентгеновской волны в кристалле становится сравнимой с амплитудой преломленной волны [4]. В этом случае интенсивность волнового поля становится зависимой от направления вектора обратной решетки [4]. Причем эта зависимость является периодической, а период стоячей волны, либо точно равен, либо в целое число раз меньше межплоскостного расстояния $d$ для рассматриваемой системы отражающих плоскостей $|\mathbf{h}|=2 \pi n / d[4]$. При этом интенсивность поля одинакова на плоскостях, параллельных отражающим плоскостям кристалла. Возникает так называемая динамическая дифракция. Малейшие нарушения в структуре кристалла приводят к разрушению периодичности и позволяют наблюдать малейшие изменения структуры кристалла $[2,4]$. Практическое использование данной методики связано с наблюдением рентгеновских фото- и оже-электронов, что требует специального прецизионного оборудования. Однако, как будет показано ниже, можно получить важные данные о структуре вещества, используя лишь незначительно модифицированный метод ПВО. В работах [9-12] была разработана методика анализа ПВО рентгеновских лучей, основанная на измерении интенсивности отраженных рентгеновских лучей при скользящем падении параксиального пучка с углом скольжения порядка 0.5'. Параксиальный пучок формировался с помощью специального параболического зеркала. Эта методика позволяет записать рентгенограмму ПВО в 
режиме $2 \theta-\theta$ и построить дифференциальную кривую ПВО, на которой явно выделяется максимум ПВО [9]. При этом оказывается, что угловое положение данного максимума характеризует показатель преломления рентгеновских лучей и связанную с ним информацию о поверхностной структуре кристалла.

Характерной особенностью ПВО рентгеновских лучей является то, что оно существенно зависит от того, какие кристаллографические плоскости, лежащие вблизи поверхности кристаллитов, расположены параллельно поверхности этих кристаллитов [10].

Цель настоящей работы - исследование модифицированным методом ПВО с использованием параболического зеркала особенностей структуры поверхности пленок карбида кремния (SiC), выращенных на кремнии $(\mathrm{Si})$ методом согласованного замещения атомов [13] в различных условиях. В работе также будет проведено сравнение пленок $\mathrm{SiC}$, выращенных на $\mathrm{Si}$ методом замещения атомов [13,14], с пленками $\mathrm{SiC}$, выращенными методом химического осаждения из паровой фазы (CVD) компанией Advanced Epi (https://advancedepi.com/sic/).

\section{2. Особенности структуры поверхности образцов SiC на Si, выращенных методом согласованного замещения атомов, и условия их синтеза для исследования методом ПВО}

Из результатов работ по синтезу $\mathrm{SiC}$ методом согласованного замещения атомов, обобщенных в обзоpax $[13,14]$, следует, что шероховатость поверхности образцов $\mathrm{SiC} / \mathrm{Si}$ в процессе синтеза пленок $\mathrm{SiC}$ претерпевает существенные изменения. В [14] приведены in situ графики зависимости изменения отражения луча света полупроводникового лазера с длинной волны $650 \mathrm{~nm}$ от поверхности кремниевой подложки, претерпевающей превращение в $\mathrm{SiC}$. В результате исследований было обнаружено, что на разных временных этапах синтеза, шероховатость поверхности как исходной подложки $\mathrm{Si}$, так и пленки $\mathrm{SiC}$, претерпевают существенные изменения. Оказалось [14], что наиболее сильные изменения структуры поверхности происходят в первые минуты (от 1 до $5 \mathrm{~min}$ ) роста слоя $\mathrm{SiC}$. При более длительных временах синтеза поверхность $\mathrm{SiC}$ сглаживается [14]. Причины изменения шероховатости связаны с особенностями образования слоев $\mathrm{SiC}$. В процессе замещения атомов $\mathrm{Si}$ на атомы $\mathrm{C}$ происходит химическое превращение $\mathrm{Si}$ в $\mathrm{SiC}$ с одновременным фазовым переходом, образованием пор в $\mathrm{Si}$ под слоем $\mathrm{SiC}$ и усадочных пор в поверхностных слоях $\mathrm{SiC}$. Подробное изложение всех протекающих процессов, их теоретический анализ и экспериментальные исследования можно найти в $[13,14]$. В [13-15] были объяснены причины существенного различия в механизмах и скоростях превращения $\mathrm{Si}$ в $\mathrm{SiC}$ на поверхностях $\mathrm{Si}(111)$ и $\mathrm{Si}(100)$.
Превращение $\mathrm{Si}$ в $\mathrm{SiC}$ происходит в результате реакции взаимодействия моноксида углерода $(\mathrm{CO})$ с кристаллическим кремнием [13-16]. Отличительной особенностью метода согласованного замещения атомов является то, что независимо от первоначальной исходной кристаллографической плоскости $\mathrm{Si}$, на которой синтезировался $\mathrm{SiC}$, обязательно в качестве одной из плоскостей образуется плоскость (111). Этот эффект связан с тем, что углеродно-вакансионные структуры всегда расположены вдоль направления $\langle 111\rangle$ и лежат в плоскости (110), перпендикулярной плоскости (111). Согласно [14] на начальной стадии превращения $\mathrm{Si}$ в $\mathrm{SiC}$ грань (100) $\mathrm{Si}$ превращается в грань $\mathrm{SiC}$, состоящую из множества фасеток, напоминающих пилообразные структуры, боковые грани которых покрыты плоскостями (111) и (110) и (210). При повышенных давлениях СО на поверхности грани (100) Si очень быстро, значительно быстрее, чем на грани (111), образуется тонкая ровная пленка SiC. Отметим, что последовательная квантовохимическая модель роста $\mathrm{SiC}$ на $\mathrm{Si}$ методом согласованного замещения атомов была изложена в работе [16].

Для анализа развития шероховатости слоев $\mathrm{SiC}$ от времени синтеза было синтезировано несколько образцов $\mathrm{SiC}$. Образцы были выращены на поверхности граней (111), (100) и (110) Si при следующих временах синтеза: 1, 4, 12, $40 \mathrm{~min}$. Температура синтеза всех образцов была равной $1270^{\circ} \mathrm{C}$. Давление газа $\mathrm{CO}$ в процессе роста поддерживалось на уровне $P_{\mathrm{CO}}=67 \mathrm{~Pa}$. Для чистоты эксперимента газообразный силан $\left(\mathrm{SiH}_{4}\right)$, который обычно добавляется к основному газу СО при синтезе $\mathrm{SiC}[13,14]$ не использовался. Для сравнения мы исследовали образцы $\mathrm{SiC}$, выращенные на $\mathrm{Si}$ стандартным методом CVD компанией Advanced Epi (https://advancedepi.com/sic/). Отметим, что в работах $[17,18]$ были исследованы пленки $\mathrm{SiC}$, выращенные на $\mathrm{Si}$ методом замещения атомов, при помощи метода рентгеновской рефлектометрии. В этих работах было обнаружено, что пленки $\mathrm{SiC}$ состоят из ряда параллельных подложке слоев, напоминающих „слоеный пирог“ с изменяющимся от поверхности по направлению к подложке Si составом. Однако, эволюция шероховатости в этих работах не исследовалась, а методика измерения ПВО была иной $[17,18]$.

\section{3. Методика измерения ПВО}

Исследования свойств монокристалла $\mathrm{Si}$ и эпитаксиальных пленок карбида кремния на поверхности $\mathrm{Si}$ проводились на рентгеновском дифрактометре ДРОН-7 с медным анодом и с параболическим зеркалом между окном рентгеновской трубки и образцом, обеспечивающем формирование параксиального рентгеновского пучка с расходимостью менее угловой минуты и подавление паразитной спектральной линии $\mathrm{CuK}_{\beta}$. Использование программного обеспечения позволило разделить спектральный дублет $\mathrm{CuK}_{\alpha 1} / \mathrm{CuK}_{\alpha 2}$ и проводить все измерения на монохроматическом рентгеновском излучении 


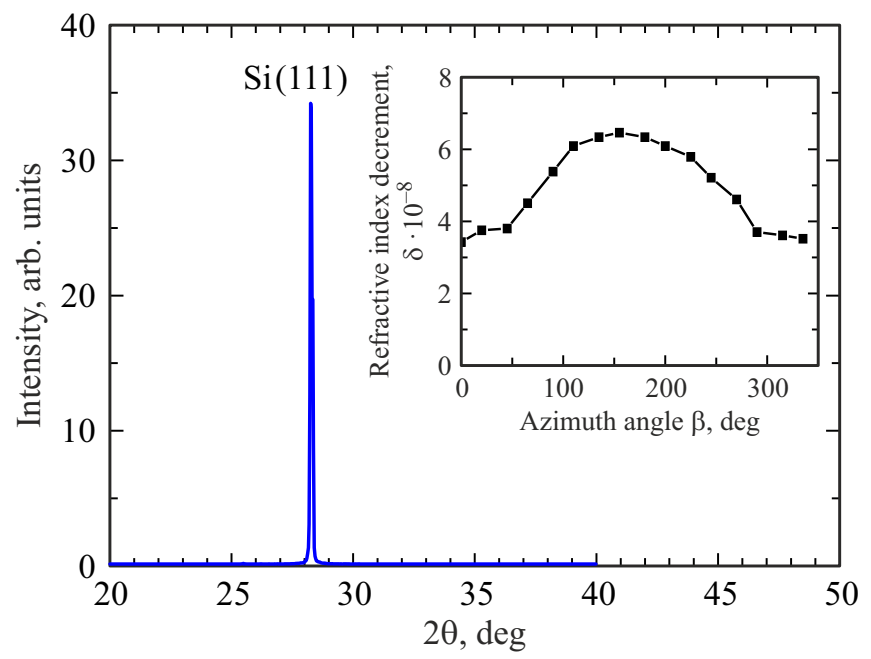

Рис. 1. Рентгеновская дифрактограмма в плоскости (111) монокристалла $\mathrm{Si}$. На вставке приведена зависимость декремента показателя преломления $\delta$ от угла поворота образца.

$\mathrm{CuK}_{\alpha 1}$ с длиной волны $\lambda=1.5406 \AA$, что соответствует энергии рентгеновского кванта $E=8048 \mathrm{eV}$. Применение параболического зеркала в сочетании с режимом измерений „2 $2 \theta-\theta^{\text {“ }}$ и коллиматором перед детектором позволило регистрировать дифференциальное полное внешнее отражение рентгеновских. Площадь проекции узкого рентгеновского пучка на поверхность образца составляет $1.6 \mathrm{~cm}^{2}$. В качестве стандартного спектра ПВО был взят спектр ПВО от поверхности (111) Si. На рис. 1 приведена рентгеновская дифрактограмма исходного образца $\mathrm{Si}$ и зависимость декремента показателя преломления в зависимости от азимутального угла поворота $\beta$.

Отметим, что дифрактограмма, представленная на рис. 1 , соответствует монокристаллическому кремнию кубической сингонии с постоянной кристаллической решетки $a=5.465 \AA$. Точка начала отсчета при построении ПВО определялась следующим образом. Для построения ПВО Si ориентации (111), вначале была снята дифрактограмма (см. рис. 1) и за точку начала отсчета был выбран максимум дифракционного пика соответствующий плоскости (111) $\mathrm{Si}$, т.е. углу $2 \theta=28.26^{\circ}$, в котором наблюдается максимальная интенсивность рентгеновской дифракции. Затем образец поворачивался на азимутальный угол $\beta$, который изменялся от $0^{\circ}$ до $357^{\circ}$ против часовой стрелки с шагом $\Delta \beta=21^{\circ}$. Через каждые $21^{\circ}$ определялся угол, при котором наблюдается ПВО. ПВО от пленок $\mathrm{SiC}$ снимались аналогично, только за точку начала отсчета принимался максимум дифракционного пика соответствующий плоскости (111) $\mathrm{SiC}$. Если у какого-либо образца $\mathrm{Si}$ с $\mathrm{SiC}$ интенсивность пика $\mathrm{SiC}$ была меньше интенсивности пика $\mathrm{Si}$, то отсчет начинался с пика Si. Этот угол для каждого из образцов незначительно отличался, поскольку деформации в пленке $\mathrm{SiC}$ приводят к смещению дифракционного пика по отношению к табличным данным дифракционного пика этой плоскости не напряженного кубического $\mathrm{SiC}$. При этом определялись углы скольжения $\alpha$. На основании значений этих углов строилась зависимость декремента показателя преломления $\delta$ от угла поворота образца. Отметим, что, как правило, кремний покрыт тонким слоем оксида. Поэтому зависимость $\delta$, приведенная на рис. 1, может быть следствием влияния оксида кремния и границы раздела Si-оксид на ПВО. В общем случае необходима специальная постановка исследований этой структуры. Отметим, что $\mathrm{SiC}$ не окисляется при комнатной температуре на воздухе, поэтому можно считать, что на его поверхности оксиды отсутствуют. Поверхность образцов $\mathrm{SiC}$, выращенных на $\mathrm{Si}(100)$ методом $[13,14]$, как показано в $[15]$, в основном покрыта гранями (111), в отличие от пленок $\mathrm{SiC}$, выращенных по стандартной методике [13], поверхность которых покрывается гранями (100). Для определения точки начала отсчета ПВО слоя $\mathrm{SiC}$, выращенного методом $[13,14]$, на $\mathrm{Si}$ (100) мы использовали дифракционный пик от плоскости (200), поскольку, как будет видно ниже, только этот пик $\mathrm{SiC}$ проявляется на пленке этой ориентации.

\section{4. Результаты эксперимента}

На рис. 2 приведены дифрактограммы и зависимости декремента показателя преломления $\delta$ от угла поворота образца для образцов $\mathrm{SiC}$, выращенных при различных временах синтеза на $\mathrm{Si}(111)$. Температура синтеза всех образцов составляла $1250^{\circ} \mathrm{C}$, давление газа $\mathrm{CO}$ было $P_{\mathrm{CO}}=67 \mathrm{~Pa}$. $\mathrm{SiH}_{4}$ при синтезе отсутствовал.

На рис. 3 представлены дифрактораммы и зависимости декремента показателя преломления $\delta$ от угла поворота для образцов $\mathrm{SiC}$, выращенных при различных временах синтеза на $\mathrm{Si}(100)$. Образцы $\mathrm{SiC}$ на $\mathrm{Si}(111)$ и $\mathrm{Si}$ (100) выращивались в одном процессе.

Для сопоставления спектров ПВО образцов $\mathrm{SiC}$, выращенных методом согласованного замещения атомов с образцами $\mathrm{SiC}$, выращенными по стандартной методике на рис. 4 приведены рентгеновские дифрактограммы и зависимости декремента показателя преломления $\delta$ от угла поворота для образцов $\mathrm{SiC}$, выращенных методом CVD (https://advancedepi.com/sic/). Исследовались пленки $\mathrm{SiC}$, выращенные на трех различных поверхностях подложек $\mathrm{Si}$, а именно на $\mathrm{Si}(111)$, на вицинальной поверхности $\mathrm{Si}(111)$, отклоненной на $4^{\circ}$ и на поверхности $\mathrm{Si}(100)$.

\section{5. Обсуждение результатов}

На рентгенограммах, приведенных на рис. 2 и 3 , хорошо прослеживается изменение во времени кристаллической структуры $\mathrm{Si}$ в процессе его превращения в $\mathrm{SiC}$ методом согласованного замещения атомов $\mathrm{Si}$ на атомы С. Особенно хорошо эволюция структуры видна на примере пленок $\mathrm{SiC}$, синтезированных на поверхности (100) Si (рис. 3).

На первой минуте синтеза на поверхности (111) $\mathrm{Si}$ появляется рефлекс, соответствующий плоскости (111) 

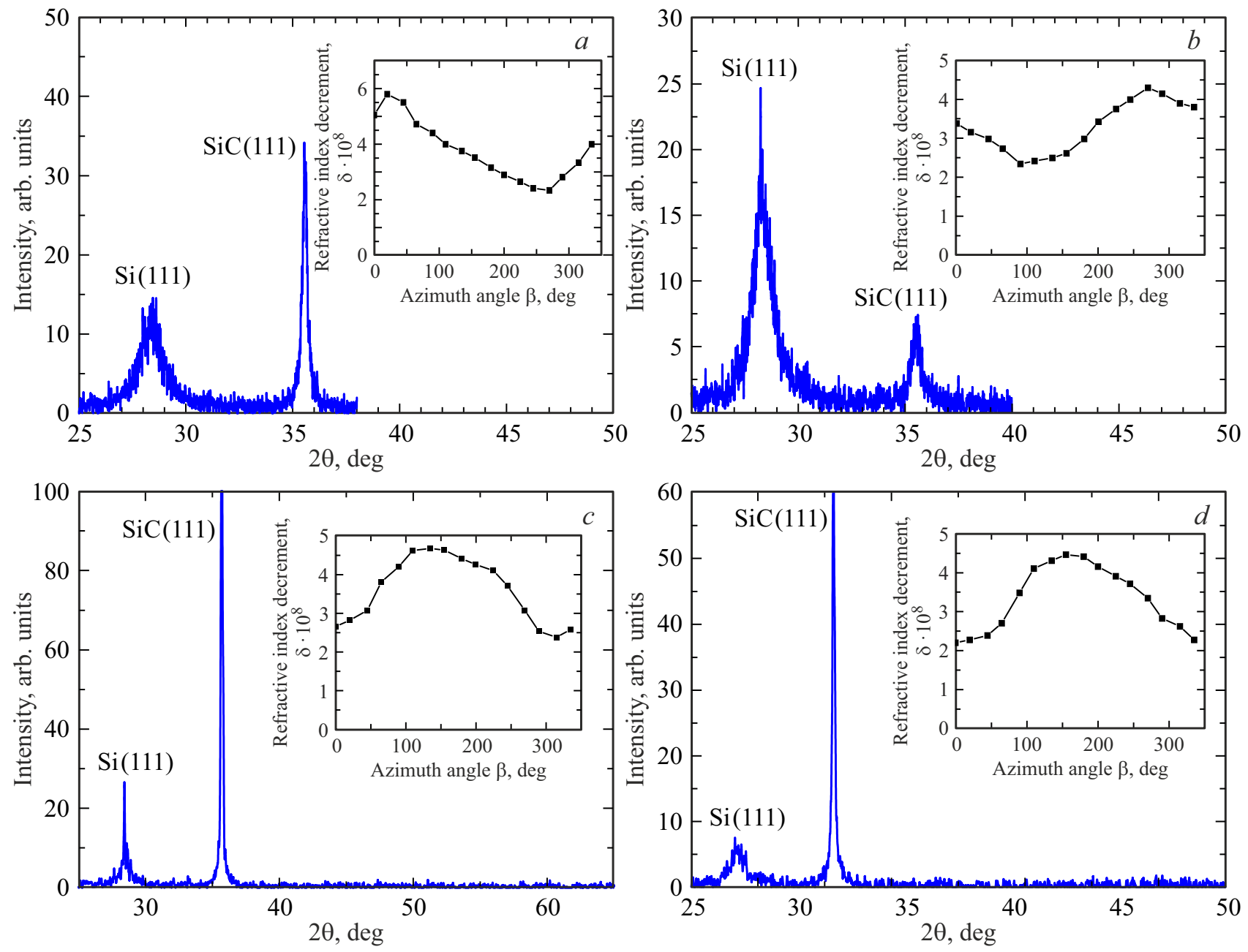

Рис. 2. Рентгеновские дифрактограммы образцов $\mathrm{SiC}$, выращенных при различных временах синтеза на $\mathrm{Si}(111)$. Времена синтеза $(a)-1 \mathrm{~min} ;(b)-4 \mathrm{~min} ;(c)-12 \mathrm{~min} ;(d)-40 \mathrm{~min}$; температура синтеза всех образцов составляла $1250^{\circ} \mathrm{C}$, давление газа $\mathrm{CO} P_{\mathrm{CO}}=67 \mathrm{~Pa}$. На вставках приведены зависимости декремента показателя преломления $\delta$ от угла поворота для этих образцов.

$\mathrm{SiC}$, а кривая зависимости декремента показателя преломления $\delta$ от угла поворота имеет вид ломаной линии. На поверхности (100) Si карбид кремния за это время еще не сформировался. Происходит интенсивное рассеяние рентгеновских лучей. Кремний находится в переходном к $\mathrm{SiC}$ состоянии. С трудом определяются только плоскости (200) $\mathrm{SiC}$ во втором порядке брэгговской дифракции и плоскость (400) кремния в его четвертом порядке. Поверхность становится очень шероховатой, поэтому нам не удалось снять спектры ПВО с этой поверхности. Ранее в обзоре [14] по отражению света от поверхности было экспериментально показано, что примерно на первых ста секундах синтеза происходит образование собственно карбида кремния из промежуточного комплекса „кремний, насыщенный кремниевыми вакансиями и углеродными атомами“", которые в $[13,14]$ названы ,дилатационными диполями“. Это образование сопровождается резкой перестройкой структуры кремния, его превращением в $\mathrm{SiC}$ с усадкой, приводящей к образованию пор и развитию шероховатости поверхности. Процесс превращения $\mathrm{Si}$ в $\mathrm{SiC}$ на поверхности (100) идет иначе [15]. На поверхности образуется структура, представляющая собой „борозды“, стенки которых покрыты гранями (фасетками) $\mathrm{SiC}$ ориентации (111). „Дно борозд“, где сходятся грани (111), представляет собой узкий участок грани с ориентацией (100). „Борозды“ ориентированы вдоль направления $\langle\overline{1} 10\rangle$. Именно поэтому при росте $\mathrm{SiC}$ вначале происходит полная перестройка поверхностного слоя $\mathrm{Si}$ и, только затем, выкристаллизовывается грань (111). Ничего подобного при росте $\mathrm{SiC}$ на $\mathrm{Si}$ стандартной методикой не наблюдается. При росте методом CVD, как и должно быть, образуются грани (100), а не грани (111). Это хорошо видно из рентгенограмм, приведенных на рис. 4. Однако, поскольку, как правило, при росте $\mathrm{SiC}$ методом CVD используются газообразные углеводороды (или пары углеродсодержащих спиртов), то и в этом случае должно происходить частичное замещение атомов $\mathrm{Si}$ на атомы С. Естественно, что этот процесс протекает иначе и более хаотично, чем процесссс с использованием реакции замещения [13]. Замещение будет „накладываться“ на основной процесс 

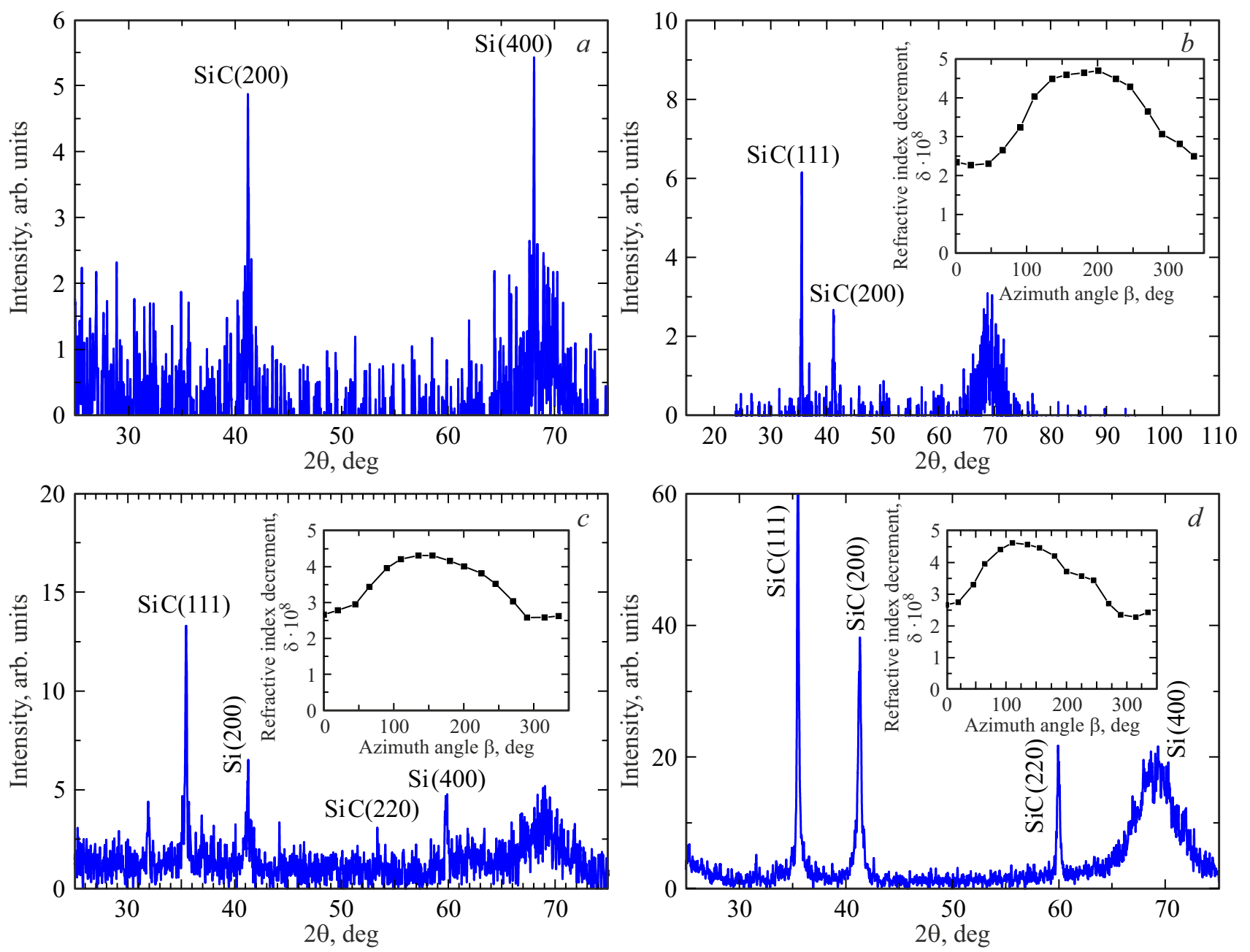

Рис. 3. Рентгеновские дифрактограммы образцов $\mathrm{SiC}$, выращенных при различных временах синтеза на $\mathrm{Si}(100)$. Времена синтеза $(a)-1 \mathrm{~min} ;(b)-4 \mathrm{~min} ;(c)-12 \mathrm{~min} ;(d)-40 \mathrm{~min}$; температура синтеза всех образцов составляла $1250^{\circ} \mathrm{C}$, давление газа СО $P_{\mathrm{CO}}=67 \mathrm{~Pa}$. $\mathrm{SiH}_{4}$ при синтезе отсутствовал. На вставках приведены зависимости декремента показателя преломления $\delta$ от угла поворота для этих образцов.

роста. По нашему мнению, именно поэтому слой $\mathrm{SiC}$ на $\mathrm{Si}$, выращенный методом (https://advancedepi.com/sic/), не обладает высоким кристаллическим совершенством, что хорошо видно на рис. 4,. .

Из рентгенограмм, приведенных на рис. 3, видно, что при времени синтеза от 1 до $4 \mathrm{~min}$ происходит формирование эпитаксиального $\mathrm{SiC}$ на поверхности грани (111) Si. Уже на $1 \mathrm{~min}$ синтеза грань (111) Si превращается в грань (111) SiC. Окончательное формирование слоя $\mathrm{SiC}$ происходит между 12 и 40 минутами синтеза. Брэгговский угол дифракции смещается в сторону больших значений, что указывает на уменьшение деформации. Смещение пиков позволяет оценить деформации, возникающие в пленках $\mathrm{SiC}$. Деформации оценивались следующим образом. В начале определялось расположение основных рентгеновских пиков первого и второго порядков (если они присутствовали) рентгенограммы на оси 20. Затем исходя из угловых положений линий и уравнения Брэгга вычислялись значения межплоскостных расстояний. Эти межплоскостные расстояния вычислялись как для пиков первого, так и второго порядков. Расчетные значения межплоскостных расстояний сравнивались с их табличными значениями для политипа $3 \mathrm{C}$-SiC. Затем вычислялись относительные деформации для плоскостей, рассчитанных исходя из пиков рентгеновских рефлексов первого и второго порядков. Как правило, они совпадали. Если и наблюдалось между ними различие, то было оно было незначительным. Если различия наблюдались, то для оценок деформаций использовалось их среднее значение. Расчеты показали следующее: в пленке $\mathrm{SiC}$, синтезированной в течение 1 min возникает деформация растяжения $\varepsilon_{111}=3 \cdot 10^{-3}$; в пленке синтезированной в течение $4 \mathrm{~min}$ деформация растяжения принимает значение $\varepsilon_{111}=2 \cdot 10^{-3}$; а в пленке синтезированной в течение 12 min деформация растяжения сменяются слабой деформацией сжатия $\varepsilon_{111}=-9 \cdot 10^{-4}$. В дальнейшем деформация остается неизменной, колеблясь, в зависимости от условий эксперимента, около нулевого значения. В пленке, синтезированной в течение $40 \mathrm{~min}$, вновь возникает деформация 
растяжения равная $\varepsilon_{111}=4 \cdot 10^{-4}$. Подобные изменения можно считать погрешностью эксперимента. Мы полагаем, что после $12 \mathrm{~min}$ деформации в пленке, вызванные
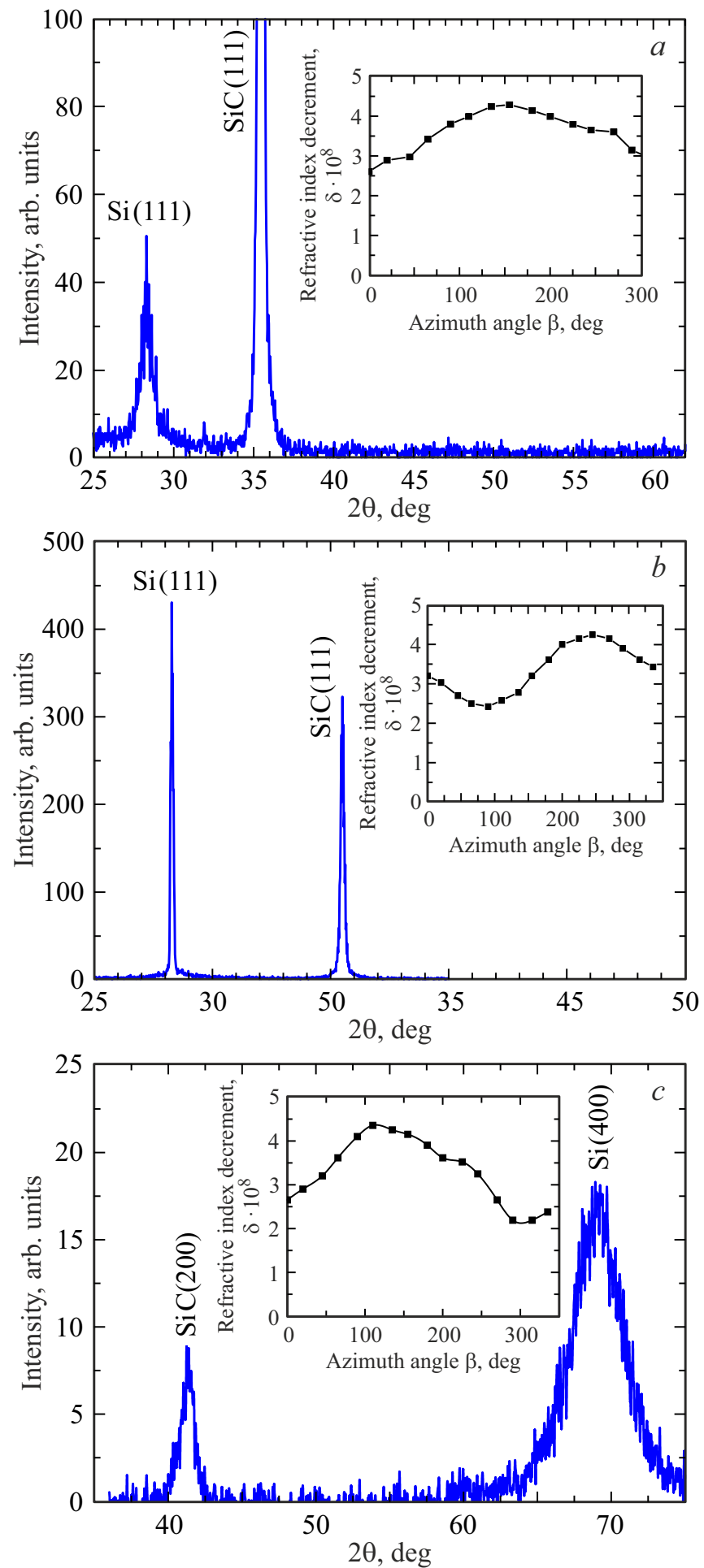

Рис. 4. Рентгеновские дифрактограммы образцов $\mathrm{SiC}$, выращенных методом CVD (https://advancedepi.com/sic/) на $\mathrm{Si}$ различной ориентации. (a) на $\mathrm{Si}(111) ;$ (b) на $\mathrm{Si}(111)$ с отклонением на $4^{\circ} ;(c)$ на $\mathrm{Si}(100)$. На вставках приведены зависимости декремента показателя преломления $\delta$ от угла поворота этих образцов. как различием в параметрах решеток, так и различием в термических коэффициентах расширения, отсутствуют. Это полностью подтверждает вывод, сделанный в $[14,16]$, о принципиальном отличии механизма роста $\mathrm{SiC}$ методом согласованного замещения атомов от классического механизма, при котором всегда при росте $\mathrm{SiC}$ на $\mathrm{Si}$ возникают деформации растяжения. Отметим, что различие в термических коэффициентах расширения нивелируются при росте $\mathrm{SiC}$ методом согласованного замещения атомов образованием пор под его поверхностью $[13,14]$.

Рассмотрим рост $\mathrm{SiC}$ на поверхности (100) Si. В полном соответствии с теорией роста, изложенной в работаx $[14,15]$, в данном случае возникают только деформации растяжения. Их величина порядка деформации на поверхности (111). Так, при временах роста 1-4 min деформации равны $\varepsilon_{100}=3 \cdot 10^{-3}$ и $\varepsilon_{111}=3 \cdot 10^{-3}$, соответственно. При временах роста $12-40 \mathrm{~min}$ деформации несколько уменьшаются и остаются на уровне $\varepsilon_{100}=5 \cdot 10^{-3}$ и $\varepsilon_{111}=5 \cdot 10^{-3}$ при 12 минутах роста и $\varepsilon_{100}=3 \cdot 10^{-3}$ и $\varepsilon_{111}=5 \cdot 10^{-3}$ для 40 минут роста, соответственно.

Рассмотрим дифрактограммы образцов $\mathrm{SiC}$, выращенных на Si методом CVD компанией Advanced Epi (https://advancedepi.com/sic/). (рис. 4). Образец SiC, выращенный на (100) Si, практически не напряжен. Это не удивительно, поскольку слой $\mathrm{SiC}$ представляет собой не эпитаксиальную пленку, а текстуру. Из рентгенограммы данного образца видно, что на ней присутствует рефлекс только второго порядка от плоскости (100). Кроме того, это следует и из не приведенных здесь данных по дифракции электронов (RHEED). Поскольку это образец является текстурированным, его деформация растяжения мала и имеет порядок примерно равный $\varepsilon_{100} \sim 9 \cdot 10^{-5}$. Образцы, полученные на (111) и на (111) с отклонением на $4^{\circ}$, растянуты. Деформация растяжения этих образцов равна $\varepsilon_{111}=5 \cdot 10^{-3}$.

Отметим, что рентгеновские данные, представленные на рис. 2 и рис. 3, приведены только для образцов $\mathrm{SiC}$, выращенных в чистом СО. В работах $[14,16,19]$ и в патенте [20] было показано, что для получения эпитаксиальной пленки высокой степени кристаллического совершенства, к газу СО необходимо добавлять в небольшой пропорции газообразный моносилан $\left(\mathrm{SiH}_{4}\right)$. Силан необходим для предотвращения излишнего испарения кремния и „залечивания“ усадочных пор, образующихся в процессе превращения $\mathrm{Si}$ в $\mathrm{SiC}$. Исследование временных зависимостей превращения, аналогичных проводимых в этой работе мы представим в отдельном исследовании, а в данной работе приведем только одну рентгеновскую дифрактограмму от слоя $\mathrm{SiC}$, выращенного из смеси газов $\mathrm{CO}$ и $\mathrm{SiH}_{4}$. Эта дифрактограмма приведена на рис. 5.

На дифрактограмме полностью отсутствуют какиелибо рефлексы $\mathrm{SiC}$ кроме основного рефлекса (111) SiC. Это говорит о высоком качестве слоя SiC. При этом слой $\mathrm{SiC}$ сжат. Деформация сжатия порядка $\varepsilon_{111} \sim-1 \cdot 10^{-3}$. Если учесть, что модуль Юнга пленки $\mathrm{SiC}$ равен 


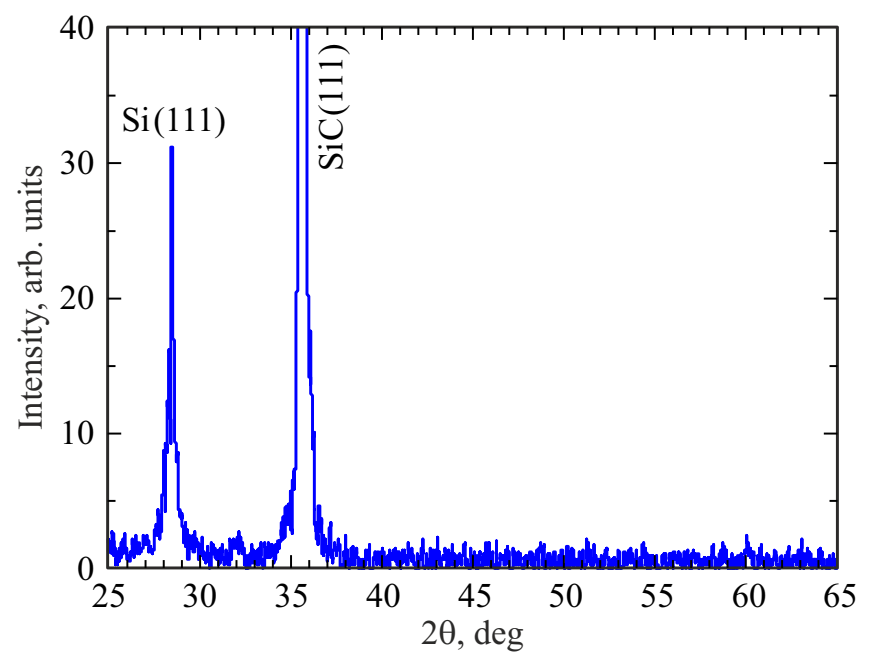

Рис. 5. Рентгеновская дифрактограмма образца $\mathrm{SiC}$ на $\mathrm{Si}$, синтезированного из смеси газов $\mathrm{CO}$ и $\mathrm{SiH}_{4}$. Температура синтеза $1290^{\circ} \mathrm{C}$, общее давление газовой смеси $P=307 \mathrm{~Pa}$, поток СО равен $12 \mathrm{~cm}^{3} / \mathrm{min}$, поток $\mathrm{SiH}_{4}$ равен $4 \mathrm{~cm}^{3} / \mathrm{min}$, время синтеза $15 \mathrm{~min}$.

$E=328 \mathrm{GPa}[21]$, а коэффициент Пуассона порядка $v \sim 0.45$, то при такой деформации, упругие сжимающие напряжения достигают величины порядка $\sigma \sim-0.6 \mathrm{GPa}$. Таким образом, меняя температуру, давление газовой смеси и скорость потока газа можно управлять упругими напряжениями, меняя их знак и величину. Отметим, что образцы, полученные методом CVD, всегда растянуты, а при росте $\mathrm{SiC}$ методом замещения атомов можно получать как растянутые, так и сжатые слои $\mathrm{SiC}$. Объяснение этого явления изложено в работах $[13,14,19]$.

На образце, выращенном при времени синтеза 4 min кривая зависимости декремента показателя преломления $\delta$ от угла поворота, как и для образца, выращенного за $1 \mathrm{~min}$, имеет вид ломанной линии, но ее максимальное значение лежит в противоположном направлении. При времени синтеза $12 \mathrm{~min}$ кривая зависимости декремента показателя преломления $\delta$ от угла поворота становится подобной аналогичной кривой чистого кремния (см. рис. 1). По нашему мнению, это говорит о завершении формирования эпитаксиального слоя $\mathrm{SiC}$. На пленках $\mathrm{SiC}$, выращенных на (100) Si, зависимости декремента индекса преломления достаточно быстро приобретают завершенный вид. Зависимости декремента индекса преломления для образцов, полученных методом CVD (https://advancedepi.com/sic/), имеют аналогичный вид, за исключением образца, выращенного на вицинальной плоскости $\mathrm{Si}$, отклоненной на $4^{\circ}$ от плоскости (111). Кривая этой зависимости подобна декременту индекса преломления для образца $\mathrm{SiC}$, синтезированного в течении $4 \mathrm{~min}$ (см. рис. 2,b). Отметим, что угловая зависимость декремента индекса преломления пленки $\mathrm{SiC}$, выращенной методом согласованного замещения атомов на вицинальной поверхности подложки $\mathrm{Si}$, отклоненной на $4^{\circ}$ от плоскости (111), имеет вид аналогичный вид (см. рис. 6,a). Такой вид зависимости декремента индекса преломления для вицинальной поверхности от угла поворота пластины связан, по нашему мнению, с рассеянием света на ступенях $\mathrm{SiC}$. Плоскости этих ступеней перпендикулярны направлению, имеющему ориентацию [1릴. Эта ориентация перпендикулярна плоскости (111). При вращении кристалла с пленкой, максимум индекса $\delta$ будет наблюдаться в момент, когда скользящий рентгеновский луч перпендикулярен плоскости ступени, т.е.

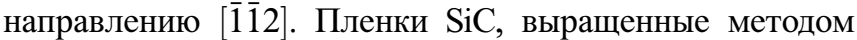
CVD на вицинальных гранях, сохранят эту ориентацию ступеней. В процессе превращения $\mathrm{Si}$ в $\mathrm{SiC}$ при росте методом согласованного замещения атомов, ступени $\mathrm{Si}$ „вытравливаются“ и покрываются гранями $\mathrm{SiC}$, в частности гранями (311) [13]. Однако, в целом, исходное

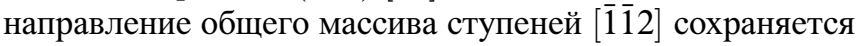
и в данном случае. Это означает что при повороте подложки $\mathrm{Si}$ с пленкой $\mathrm{SiC}$ на $270^{\circ}$ угол ПВО возрастает, что ведет к росту декремента индекса преломления $\delta$. Это хорошо видно как на пленке, выращенной методом CVD (рис. 5), так и на пленке $\mathrm{SiC}$, выращенной методом замещения атомов (рис. 6,a). Для подтверждения этого методом замещения был выращен слой $\mathrm{SiC}$ на поверхности $\mathrm{Si}(110)$. Температура синтеза пленки составляла $1290^{\circ} \mathrm{C}$, давление газа СО $P_{\mathrm{CO}}=67 \mathrm{~Pa} . \mathrm{SiH}_{4}$ при синтезе отсутствовал. Образец выращивался в течение $30 \mathrm{~min}$. На рис. $6, b$ приведена рентгенограмма этого образца, а на вставке к ней зависимость его декремента показателя преломления $\delta$.

Для выяснения причин влияния кривизны пластины и ее шероховатости на рентгеновские характеристики были построены аналогичные зависимости декремента показателя преломления $\delta$ от азимутального угла поворота для пластины, изготовленной из меди. Медь была выбрана по двум причинам. Во-первых, как кремний и как кубический политип карбида кремния, медь кристаллизуется в кубическую гранецентрированную решетку (с тем лишь отличием, что решетка $\mathrm{SiC}$ алмазного типа). Во-вторых, медь - это металл, а не полупроводник, поэтому интересно проверить будут ли формы кривых ПВО у металла и полупроводника различаться. Согласно теории [6] и формуле (1) этого не должно наблюдаться. Исходная медная пластина, состоящая из поликристаллической меди, была отполирована. С ее поверхности были сняты ПВО и XRD дифрактограмма. Затем на поверхность этой пластины в одном направлении были нанесены углубленные борозды. После этого вновь c еe поверхности были сняты ПВО и XRD дифрактограмма. Зависимости декремента $\delta$ для медной пластины приведены на рис. $6, c$. Из этих данных следует, что зависимости декремента $\delta$ для полированной и шероховатой поверхностей отличаются друг от друга. Поведение декремента $\delta$ для полированной поверхности, как можно видеть, схоже с поведением декремента для слоя $\mathrm{SiC}$, выращенного на $\mathrm{Si}(111)$ и $\mathrm{Si}(100)$, на завершающей стадии его формирования. На шероховатой поверхности медной пластины зависимость декремента $\delta$ от азимутального угла напоминает его поведение на начальных этапах 

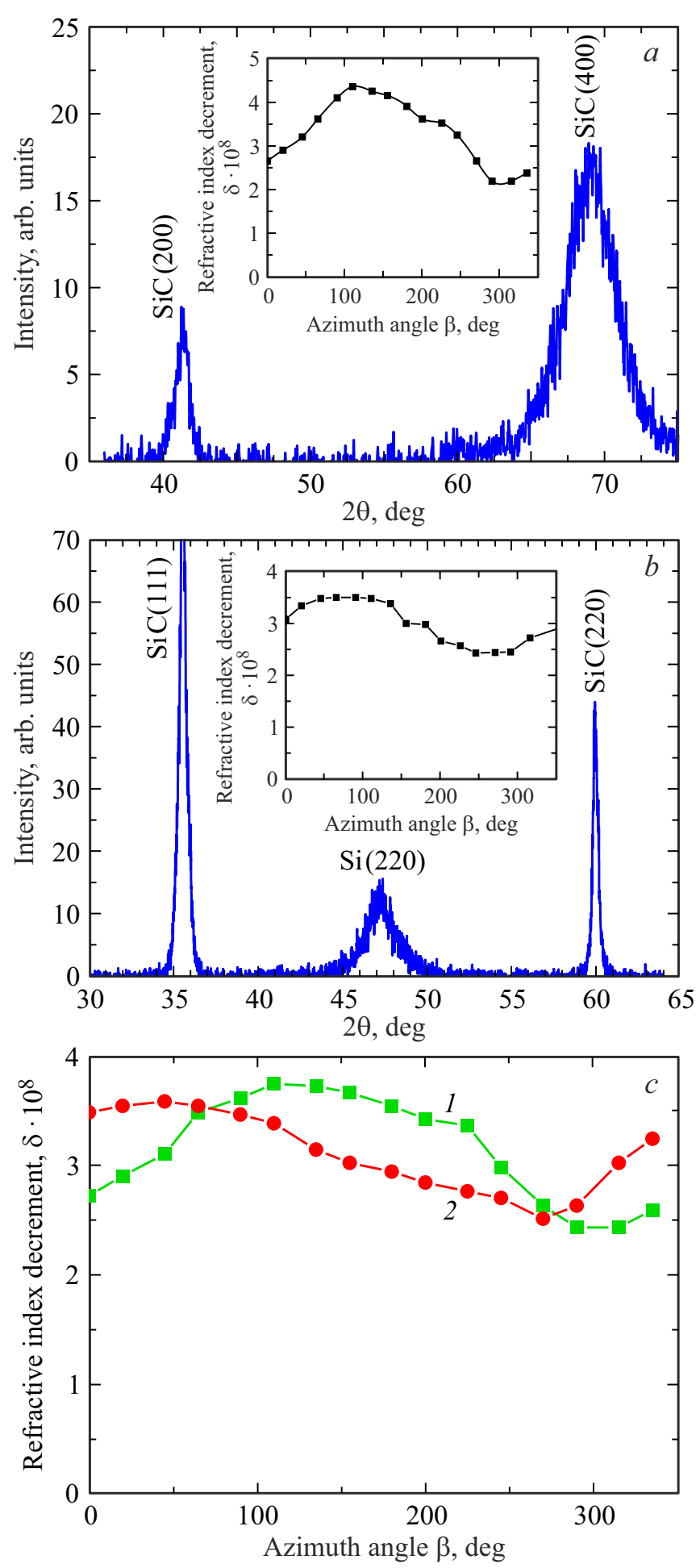

Рис. 6. Зависимости декремента показателя преломления $\delta$ от угла поворота различных образцов; $(a)$ - образца $\mathrm{SiC}$, выращенного методом замещения атомов на $\mathrm{Si}(111)$ с отклонением на $4^{\circ} ;(b)-\mathrm{XRD}$ дифрактограмма образца $\mathrm{SiC} / \mathrm{Si}(110)$ и зависимость его декремента показателя преломления $\delta$ (на вставке) от угла поворота образца $\mathrm{SiC}$, выращенного на $\mathrm{Si}(110) ;(c)$ - зависимость декремента показателя преломления $\delta$ от угла поворота медной пластины; 1 - кривая для полированной поверхности медной пластины; 2 - кривая для медной пластины с нанесенными на ее поверхность бороздами. формирования $\mathrm{SiC}$ на (111) и на поверхности (110). Это, а также поведение индекса $\delta$ для поверхности (110) $\mathrm{SiC}$, дает объяснение поведения величины и на поверхностях $\mathrm{SiC}(111)$. Действительно, обратимся к рис. 2,a. Максимальное значение декремент индекса преломления $\delta$ при $1 \mathrm{~min}$ роста слоя $\mathrm{SiC}$ принимает, если скользящий рентгеновский луч направлен вдоль направления $\langle 1 \overline{1} 0\rangle$. Минимальное свое значение свое значение он достигает при повороте образца на $270^{\circ}$. Это означает, что именно вдоль этого направления происходят основные изменения структуры как $\mathrm{Si}$, так и $\mathrm{SiC}$ в самые первые минуты синтеза. Собственно, это следует и из вида дифрактограмы (рис. 2, a), о которой говорилось выше. Дифракционный пик $\mathrm{SiC}$ выше пика $\mathrm{Si}$. При этом оба пика достаточно размыты, что говорит о перестройке структуры. Очевидно, что вдоль направления $\langle 1 \overline{1} 0\rangle$ возникает прогиб пластины, что ведет к росту угла отражения. Через три минуты синтеза картина кардинально меняется (рис. $2, b$ ). Кривая декремента индекса преломления $\delta$ принимает вид, аналогичный виду декремента индекса преломления $\delta$ для пленок выращенных на вицинальных поверхностях $\mathrm{Si}$ (рис. 5 и рис. 6). Меняется и рентгеновский спектр. Интенсивность пика от кремния возрастает, тогда как интенсивность пика (111) SiC уменьшается.

По экспериментальному значению декремента индекса преломления $\delta$ и формуле (1) можно оценить объемную плотность рассеивающих атомов $N_{a V}$ в зоне выхода ПВО [10]. На основании оценок величины $N_{a V}$, расчета глубины формирования ПВО в материале, оценок пробега рентгеновского кванта в веществе [22], можно оценить плотность локализованных электронов $N_{0}[23,24]$, участвующих в формировании ПВО рентгеновских лучей. Поскольку плазменные колебания в твердом теле возбуждаются не квантами рентгеновского излучения, а медленными вторичными электронами, порожденными быстрыми рентгеновскими фотоэлектронами [25] в тонком поверхностном слое толщиной $\lambda$, то эту толщину, с которой происходит выход из твердого тела медленных электронов, следует вычислять по формуле Бронштейна [26]:

$$
\lambda=\frac{1.9 \cdot 10^{-7} \cdot A}{\rho \cdot Z^{0.6}},
$$

где $A-$ атомная масса; $\rho-$ плотность; $Z-$ порядковый номер элемента. Следует отметить, что плазменные колебания, возбуждаемые рентгеновским излучением это колебания связанных электронов, согласно [23] их частота соответствует большой энергии. Эти колебания не возбуждаются при тепловых энергиях. Согласно [23] энергии плазменных колебаний нельзя отождествлять с оптической щелью между потолком валентной зоны и дном зоны проводимости. Эта энергия соответствует среднему расстоянию между энергетическими уровнями, расположенными вертикально, друг над другом в приведенной зоне Бриллюэна [23].

На основании этих данных можно оценить плотность электронов, участвующих в возбуждении плазмонов, а 
затем оценить энергию возбуждаемых рентгеновском излучением при ПВО плазмонов. Более подробно с этой методикой можно ознакомиться в работах [7-10]. Выше на основании анализа, проведенного в [6], мы отмечали, что нужно с осторожностью подходить к оценке энергии плазмонов при использовании формулы (1), поскольку в общем случае показатель преломления может зависеть от пространственных координат. Похоже, что именно это и наблюдается в процессе измерения декремента $\delta$ при вращении образца. Поэтому для оценок энергии плазмонов у каждого из образцов $\mathrm{SiC}$ мы брали только минимальное значение $\delta$, т.е. для каждого образца использовалось только минимальное значение угла ПВО, которое приведено на вставках к соответствующим рентгенограммам. На основе этих значений $\delta$ и были оценены энергии плазмонов $E_{P}$. Так для $\mathrm{Si}$ энергия $E_{P}=2.11 \mathrm{eV}$; для слоя $\mathrm{SiC} / \mathrm{Si}(111) 4^{\circ}$ $E_{P}=1.74 \mathrm{eV}$; для слоя $\mathrm{SiC} / \mathrm{Si}(111)$, синтезированного в течение $1 \mathrm{~min} E_{P}=1.74 \mathrm{eV}$; для слоя $\mathrm{SiC} / \mathrm{Si}(111)$, синтезированного в течение $4 \min E_{P}=1.74 \mathrm{eV}$; для слоя $\mathrm{SiC} / \mathrm{Si}(111)$, синтезированного в течение $40 \mathrm{~min}$ $E_{P}=1.74 \mathrm{eV}$; для слоя $\mathrm{SiC} / \mathrm{Si}(1100) E_{P}=1.71 \mathrm{eV}$. Для образов, выращенных методом CVD, значения $E_{P}$ следующие: для образца $\mathrm{SiC} / \mathrm{Si}(111) E_{P}=1.85 \mathrm{eV}$; для образца $\mathrm{SiC} / \mathrm{Si}(111) 4^{\circ} E_{P}=1.75 \mathrm{eV}$; для образца $\mathrm{SiC} / \mathrm{Si}(100)$ $E_{P}=1.6 \mathrm{eV}$. Еще раз отметим, что измеренные значения энергий $E_{P}$, нельзя отождествлять с оптической шириной запрещенных зон, хотя их значения могут быть и близки, что наблюдается в данном случае, особенно для образцов $\mathrm{SiC}$. Выше мы отмечали, что $\mathrm{Si}$, как правило, покрыт слоем оксида, поэтому энергия $E_{P}=2.11 \mathrm{eV}$ может соответствовать не чистому $\mathrm{Si}$, а $\mathrm{Si}$ со слоем оксида. Из проведенных данных следует, что энергии $E_{P}$ у слоев $\mathrm{SiC}$, полученных как методом CVD, так и методом замещения, но без добавления силана, близки по значению. При добавлении силана к газу $\mathrm{CO}$ в процессе синтеза, значения энергий $E_{P}$ для слоя $\mathrm{SiC}$ возрастает. Это, по нашему мнению, свидетельствует о повышении совершенства кристаллической структуры пленок. Так у образца, чей рентгеновский спектр приведен на рис. $5, E_{P}=2.5 \mathrm{eV}$. Для сравнения, методом ПВО была снята угловая зависимость декремента $\delta$ монокристалла $4 H-\mathrm{SiC}$ (эти данные за не имеем места здесь не приводятся). Значение энергии $E_{P}$ оказалось равным $E_{P}=2.7 \mathrm{eV}$, что близко к значению $E_{P}$ для образца $\mathrm{SiC}$, выращенного в присутствии силана. Таким образом, величина энергий $E_{P}$ может качественно свидетельствовать о наличии или отсутствии дефектов в кристалле.

\section{6. Заключение}

При совместном использовании методов рентгенографии и ПВО рентгеновских лучей для исследования временных этапов синтеза эпитаксиальных пленок $\mathrm{SiC}$ на $\mathrm{Si}$ получены данные об эволюции превращения поверхностей (100), (110) и (111) $\mathrm{Si}$ в поверхности
$\mathrm{SiC}$ в процессе согласованного замещения части атомов $\mathrm{Si}$ на атомы С. Обнаружено, что окончательное формирование слоя $\mathrm{SiC}$ при температуре $1250-1300^{\circ}$ завершается между 15 и 30 мин. синтеза. Подтверждено обнаруженное ранее $[14,15]$ явление образования граней (111), как основных граней на поверхности (100) и (110) $\mathrm{Si}$ при использовании метода замещения атомов. На примере образцов, изготовленных фирмой Advanced Epi (https://advancedepi.com/sic/), показано, что при использовании стандартного CVD метода роста на поверхности грани (100) Si всегда образуется грань (100) SiC. Подтвержден ранее обнаруженный факт $[13,14,16,19,20]$ значительного улучшения кристаллического качества слоев $\mathrm{SiC}$ и смены растягивающих упругих наряженный в слое $\mathrm{SiC}$ на сжимающие при добавлении газообразного силана к газу СО. Показано, что экспериментальное измерение величины декремента показателя индекса преломления $\delta$ при помощи ПВО дает важную информацию о эволюции кристаллической структуры в процессе превращения $\mathrm{Si}$ в $\mathrm{SiC}$.

\section{Благодарности}

Авторы признательны В.К. Егорову за полезное обсуждение ряда вопросов, касающихся ПВО рентгеновских лучей.

\section{Финансирование работы}

Работа была выполнена в рамках проекта Российского научного фонда № 20-12-00193.

Исследования проводились с использованием оборудования уникальной научной установки „Физика, химия и механика кристаллов и тонких пленок“" ФГУП ИПМаш РАН (Санкт-Петербург).

\section{Конфликт интересов}

Авторы заявляют, что у них нет конфликта интересов.

\section{Список литературы}

[1] P.F. Fewster Rep. Prog. Phys. 59, 1339 (1996). DOI: $10.1088 / 0034-4885 / 59 / 11 / 001$.

[2] М.А. Щербина, С.Н. Чвалун, С.А. Пономаренко, М.В. Ковальчук. Успехи химии. 83, 12, 1091 (2014). http://dx.doi.org/10.1070/RCR4485?locatt=label:RUSSIAN.

[3] В.Е. Асадчиков, Е.Е. Андреев, А.В. Виноградов, А.Ю. Карабеков, И.В. Кожевников, Ю.С. Кривоносов, А.А. Постиов, С.И. Сагитов. Поверхность. Рентгеновские, синхротронные и нейтронные исследования. 7, 17 (1998).

[4] М.В. Ковальчук, В.Г. Кон. УФН 149, 69 (1986).

[5] D.K.G. de Boer. Phys. Rev. B 51, 5297 (1995).

[6] Р. Джеймс. Оптические принципы дифракции рентгеновских лучей. Из-во ИЛ, М.(1950). 572 c. [R. James. Optical Principles of the Diffraction of X-Rays. Ox Bow Pr (1982). ISBN-10: 0918024234]. 
[7] П. Чижов, Э. Левин, А. Митяев, А. Тимофеев. Приборы и методы рентгеновской дифракции. Можайский полиграф. комбинат, Можайск (2011). $151 \mathrm{c.}$

[8] Л.Д. Ландау, Е.М. Лифшиц. Теоретическая физика. Электродинамика сплошных сред. Наука, М. (1992). T. VIII. $663 \mathrm{c}$.

[9] В.М. Стожаров. ЖТФ 87, 125 (2017).

[10] В.М. Стожаров, В.П. Пронин. ЖТФ 87, 1901 (2017).

[11] В.М. Стожаров. ЖТФ 89, 1042 (2019).

[12] В.М. Стожаров. ЖТФ 90, 1116 (2020).

[13] С.А. Кукушкин, А.В. Осипов, Н.А. Феоктистов. ФТТ 56, 1457 (2014).

[14] S.A. Kukushkin, A.V. Osipov. J. Phys. D 47, 313001 (2014). DOI:10.1088/0022-3727/47/31/313001.

[15] S.A. Kukushkin, A.V. Osipov, I.P. Soshnikov. Rev. Adv. Mater. Sci. 52, 29 (2017).

[16] S.A. Kukushkin, A.V. Osipov. J. Phys. D. 50, 464006 (2017).

[17] С.А. Кукушкин, К.Х. Нусупов, А.В. Осипов, Н.Б. Бейсенханов, Д.И. Бакранова. ФТТ 59, 986 (2017).

[18] S.A. Kukushkin, K.Kh. Nussupov, A.V. Osipov, N.B. Beisenkhanov, D.I. Bakranova. Superlat. Microstruct. 111, 899 (2017).

[19] С.А. Кукушкин, А.В. Осипов. Письма в ЖТФ 43, 81 (2017). DOI: 10.21883 /FTT.2022.03.52093.232

[20] С.Г. Жуков, С.А. Кукушкин, А.В. Лукьянов, А.В. Осипов, Н.А. Феоктистов. Способ изготовления изделий, содержащих кремниевую подложку с пленкой из карбида кремния на ее поверхности. Патент № 2522812 РФ от 21.05.2014.

[21] А.С. Гращенко, С.А. Кукушкин, А.В. Осипов. ФТТ 61, 2313 (2019). DOI: 10.1134/S106378341912014X.

[22] М.В. Давидович. Оптика и спектроскопия 126, 3, 360 (2019). DOI: 10.21883/FTT.2022.03.52093.232

[23] Дж. Займан. Принципы теории твердого тела. Мир, М. (1966). 315 c.

[24] П. Гроссе. Свободные электроны в твердых телах. Мир, M. (1982). 470 c.

[25] В.А. Волков. Плазмоны и магнитоплазмоны. ИРЭ РАН, М. (2019). C. 1-7.

[26] И.М. Бронштейн, Б.С. Фрайман. Вторичная электронная эмиссия. Наука, М. (1969). 174 с.

Редактор Ю.Э. Китаев 